\title{
Towards a Trans-Mediterranean Partnership for Peace?
}

\section{Alain Faupin *}

I am convinced that the common and frequent use of certain words sometimes blurs their true meaning. But when one takes the precaution of asking oneself, just before taking hold of a problem, "What's up?" one comes to grip with the ideas behind the words, which the topic really deals with. This is what I did in this case. What does one really mean by "Partnership for Peace" and by "the Mediterranean"? The answers to these questions led me to wonder about the points of application of this "partnership": on one side, a world that it has helped to restructure since the end of the Cold War, on the red ashes of the Soviet empire; on the other side, a fractured world in search of peace, stability, security, and development. This situation can suggest three different approaches: a long preparatory phase; a common sense solution, progressive and limited in scope; or an offensive and wide-ranging approach.

The question of the role of this "partnership" is not a recent one. An abundant literature has emerged on this topic, but has not resolved the question. It is appropriate for this issue to be back on the table at a time when the Euro-Atlantic partnership has either met most of its goals or reached the limit of its sphere of action and when NATO, confronted with the absence of an enemy, is forced to develop a new raison d'être that can justify its survival. Is the situation that urgent? It is true that security and stability cannot wait, although they are long-term objectives. It is precisely for that reason that one should not delay the preparation of the ground, as Marshal Lyautey, a long-time Governor General of Morocco, once put it. ${ }^{1}$

The Istanbul Summit, the ongoing war against terrorism, the aftermath of the Iraqi campaign, the willingness to promote economic growth but the persistence of dramatic underdevelopment lead us to start thinking of the role of a "Partnership for Peace." But it is not possible to deal with everything at the same time. The question needs to be well framed, and the answer should encompass all the relevant aspects of the topic. Are we to speak about defense and security in general, or concentrate on defense? Do we include all the actors within the security sector, or just the armed forces? Such questions are potentially endless.

\section{From Semantics to Praxis}

Let us focus now on an analysis of "a Trans-Mediterranean Partnership for Peace." A "partner" is a part of a whole. It can be an entity with which another entity is allied against other players in a game or in a geographic ensemble. A partner is a person with whom we discuss. A partner can also be a community with which another community has relations and exchanges.

\footnotetext{
Major General Faupin, DCAF.
}

When his decision to reforest the Atlas Mountains in Morocco with cedar trees was questioned by a civil servant, on the grounds that they grew very slowly, he told him: "... no better argument to begin without delay!" 
As far as "partnership" is concerned, let's define it here as an association of enterprises and of institutions gathered in view of accomplishing a common goal. This implies an agreement, if not an actual alliance.

"Peace" is a very vague notion, which can be understood as the absence of war, or as the political, economic, and judicial combination that allows that condition to last as long as possible. There are different sorts and different degrees of peace: armed peace; local peace; peace that is beneficial to some and damaging to others; Paxæ Romana, Africana, Americana, Arabica, Europeana... and the eternal peace!

What exactly does "trans-Mediterranean" mean? It has two close but not identical meanings: one is "on the other side of the Mediterranean," which therefore excludes the sea itself; the other is "through the Mediterranean," designating less clearly what is on the other side of the sea.

Last but not least, of what "Mediterranean" do we speak? Is it of this gigantic lake in the middle of lands with its two crashed basins - the Black and the Red Seaswhich make the Mediterranean entity a region in itself, bordered on the four cardinal points? It is also possible to slice it into five sections: the two annexed seas, the Western Mediterranean, the Central Mediterranean, and the Eastern Mediterranean. There is also the north rim and the south rim. This multiplicity shows how necessary it is to come up with a clear definition. And this is not obvious, but rather a matter of point of view.

Taking stock of all the above, what about the notion of a "Trans-Mediterranean partnership"? Against whom? Against no one, but in search of peace, alongside familiar players who know one another, respect their partners, and who have already opposed each other in earlier instances? With players who might not be in the same geographic situation: maritime states or countries of the hinterland? What do Norway and Algeria have in common? Oil? One can speak with "discussion partners," and that has been going on (and on), endlessly, for years and centuries - peace plans, road maps, good offices, mediations, negotiations - to very little avail. There are also "deep love" relationships, based upon strong feelings, but also relationships of disenchantment, as sudden and as strong, between familiar partners. Would this all fall under "the Partnership"?

In practical terms, everybody knows what the NATO Partnership for Peace is made of: its objectives, its financing, and its major activities are mainly intended for peace operations. The enlargement of NATO has made its evolution unavoidable.

The PfP, as an initiative of cooperative security, is anything but rigid, and has just enough political goals (such as protecting human rights, safeguarding individual liberties, promoting democracy, fostering democratic control of the armed forces) to make it possible to deal technically and fundamentally with its fields of competence, among which is preparation for peacekeeping operations. The Euro-Atlantic Partnership Council (EAPC) shows that the partners need to have a new framework for international consultation, just as the Partnership Action Plan (PAP) shows that they intend to increase their interoperability, a sine qua non condition for efficiency in any given peacekeeping operation. 
The PfP has contributed to the reconstruction of a region that was divided during the Cold War into two different worlds, and has helped to recreate a homogeneous region: the Euro-Atlantic area. This is a region characterized by real geographic continuity and a genuine identity, built out of cultural, economic, monetary, and conceptual (not to say political) elements.

The reconciliation processes that are so important to reunifying the region, with very few exceptions (Cyprus being an ugly one), have been achieved. This move is more fundamental and has more structural implications than any other action that the PfP has undertaken. The OSCE and the EU have helped, but it is obvious that the PfP has accelerated the trend. The challenges faced by this rejuvenated Europe are shared and often common. They sometimes turn into threats, but they generally consist in societal problems that have been generated both inside and beyond the borders of individual member states, which are increasingly common borders. The Mediterranean is one of them, the most porous of all. Europe is now a coherent and cohesive entity.

\section{A Recomposed World Facing a Fractured World}

The Partnership for Peace has powerfully contributed to the restoration of Europe's geographic continuity by filling the fissures created and kept open through constraint by the Soviet system and the Warsaw Pact. The end of the Cold War and the birth of new states, as well as the quick return to democratic practices in the former Soviet satellite states, have allowed NATO to bridge the remaining gaps. This initiative expressed clearly the will of the populations to rejoin the Western family, from which force and ideology had kept them separated for forty years. It has emerged as a major factor of commonality among the different communities of our continent, one that is based on shared values (democracy ranking first), rather than on diverging interests. The European Union has also made a significant contribution (along with the OSCE over the past ten years) to institute the rule of law in a manner that is economically sound, socially coherent, and security-minded.

Facing a great variety of both old and new challenges, behind common borders, Europe now has to refurbish its defense tools. The PfP has already contributed to this endeavor, but is now reaching the limits of its competencies. It needs a new geopolitical raison d'etre: either by expanding to the east (PAP-DIB) ${ }^{2}$; by expanding to the south of the Mediterranean or to the greater Middle East; or by taking over new missions, as recommended in Prague (PAP), especially with regard to anti-terrorist policies. However, it is obvious that, in so doing, we would jeopardize the geographic continuity and the cultural homogeneity that we have achieved thus far.

With the exception of a few common points between the northern and the southern rim of the Mediterranean, such as olive oil, scarce water, hot sun, Islam, cultural mosaics, and less than brilliant economies, this region is deeply fractured. Last but not least, active plate tectonics often add their catastrophic note to a relatively dull picture.

2 Partnership Action Plan - Defense Institution Building. 
As we have seen, there are five "small Mediterraneans," if we take into account the Black and the Red Sea annexes. Economics divides more than it unites; the flows of exchange are, with the exception of oil and gas, more North-South than South-North. Natural resources are unevenly shared, and the soaring demographic growth in the region remains one of the main causes of underdevelopment and of insecurity. These social and economic problems, used by Islamist fundamentalists and extremists for political gain, are the wellspring of most of the region's internal unrest, and of much international turmoil as well.

Security systems in the region vary from one country to another, but none (except the Israeli security apparatus) is controlled by the parliament. Besides, there is almost no security cooperation between the countries in the region at any level: bilateral, subregional, or regional. "Fragmented" is another adjective that would aptly characterize the South, which only unites when it comes to the conflict involving Israel and the Palestinian Authority. The Arab world has tried several times to unite, but has only succeeded occasionally, and then largely only at the level of words. National interests are too divergent, denominations are too exclusive, and alignments are too strong; all of these are perennial sources of division. Only a lengthy process of reconciliation could overcome these divisions, provided it were sustained by a strong political and democratic will.

\section{Solutions}

Nothing can or should be undertaken between the North and the South without the formal agreement of the nation states involved (I could have said "of the populations"). The decision should be theirs. The principle of ownership should apply fully and be totally respected; that is the first and major condition for the success of any NorthSouth initiative.

Government structures in the South are for the most part authoritarian. It would be completely unrealistic to ask the population of these nations to give their say on a program of armament or the engagement of forces in a peacekeeping operation, or even for the reform of the security sector. The point of departure to promote a change in the mindset is therefore a personal commitment of the heads of state and of government themselves. From there, two options are open.

The first, inspired by a rigorous and cautious analysis, would be based on a clear identification of the security challenges, capabilities, and needs in a given geographical area. Such options would be limited in space, time, and scope, and would be implemented in a slow but reasonable process.

The second would answer the West's impatient quest for security. The West has shown itself eager to intervene on a larger geographical scale and on a greater number of issues in pursuit of solutions to its own security concerns. This would be a quicker but riskier process.

3 The only exceptions are the Turkish-Israeli cooperation agreement, and, of course, Turkey itself, a member of NATO. 
What seems evident to us in the North is probably not as clear to our partners in the South, where the system of values is different - neither better nor worse, simply different. Our American, Spanish, British, and Polish friends (to name a few of the seventeen NATO countries currently involved in the conflict in Iraq) can testify to that. There are more trivial expressions in use to convey the idea that one cannot be forced in a project if one is not convinced. ${ }^{4}$ I shall therefore insist again that nation-states - and, if possible, populations and their parliamentary representatives - take hold of these initiatives and succeed in persuading their respective countries of their necessity.

Beyond this is the need to organize a formal engagement-followed by practical measures - to contribute to the resolution of the Israeli-Palestinian issue by helping all the stakeholders to reach an agreement and to conclude it. This engagement would also aim at easing the tensions that exist between neighbors, whatever their causes, both in their degree of intensity and their extent.

The states in the region must also strive to improve their institutions, to make them more transparent, more democratic, and less prone to arbitrariness and corruption. Finally, the dialogue frameworks (NATO, Barcelona, bilateral) should remain wide open during the entire duration of the exercise. Only these structures can allow for the exchange of ideas, the elaboration of proposals, and eventually the transfer of expertise.

Once the prerequisites are met, the installment of a partnership would be possible under the following conditions:

1. The goals would focus on progressively improving interoperability between the armed forces of states in the North and the South, whatever their institutional involvement is (EU, NATO, OSCE, UN). Three areas should then be focused on and be provided with the same assets as in the Euro-Atlantic area.

- The first area is the education of defense personnel, civilian and military alike; this is already conducted through bilateral cooperation agreements. The signing of a partnership protocol would speed up the process and provide additional assets, as well as a common doctrine.

- The second area is training in military techniques (with adapted assets) in the fields of leadership, planning, command and control, communication and logistics, etc.

- The third area directly precedes the operational engagement of forces and aims at shaping them to that end. It consists of national, regional, and international exercises.

2. The second condition is to focus only on operations that are in the humanitarian realm, or fall under the rubric of the "Petersberg tasks," whatever organization (NATO, EU, OSCE, UN) has the mandate of conducting and controlling them.

4 "You can lead a horse to water, but you can't make it drink" being the best known. 
3. The third area is that of a common system intended to administer, advise, animate, control, and monitor this new partnership for peace.

These goals can be seen as modest, and not sufficiently ambitious. They would, however, represent a significant leap forward, and their implementation would take time. Indeed, what is important here is to ensure that not one or two countries of the southern rim participate in the implementation of such programs, but that all of them do so, and together.

Meanwhile, it would be totally ineffective and incoherent to transpose the European experience to the South, because we do not share the same ideas about events, geography, and the use of force. Furthermore, any move that could be associated with the notion of Western pressure would be sooner or later rejected. The endeavor is therefore a difficult one, and appears to be not so promising. The prerequisites are capital. The expansion of the territorial limits of the Partnership beyond the maritime states of the Mediterranean does not seem realistic, and all the current warning lights and indicators are advising against such a trend. The nation-states of the so-called "Greater Middle East" are clearly reserved in their enthusiasm as far as the involvement of the West in their own business is concerned.

\section{Conclusion}

In conclusion, let me sum up some of the key elements that such an effort must take into consideration:

- Time factor: what is the exact degree of urgency?

- The extreme and growing geopolitical complexity and diversity of the region;

- The importance of national, cultural, and religious sensitivities;

- The diverging security perceptions between the North and the South;

- The assets (dialogue, cooperation, evolution of the mindset and of the rule of law);

- The need for transparency and for ownership.

Under these conditions, and with cautious, intelligent, and proper handling, it is possible to envisage a trans-Mediterranean partnership for peace. 